
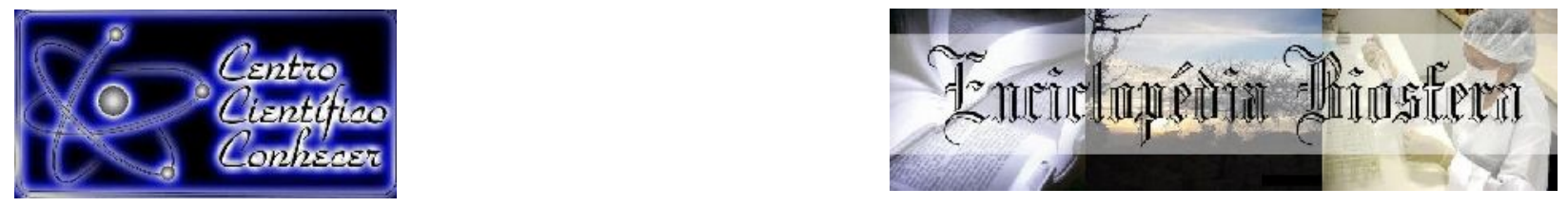

\title{
SUPERAÇÃO DA DORMÊNCIA DE SEMENTES DE Senna multijuga (Rich.) H. S. Irwin \& Barneby COM O USO DE LIXA EM CILINDRO ROTATIVO
}

\author{
Evandro Luiz Missio ${ }^{1}$, Cleber Witt Saldanha ${ }^{2}$, Rosana Matos de Morais ${ }^{3}$, Gerusa \\ Pauli Kist Steffen ${ }^{4}$, Joseila Maldaner ${ }^{5}$ \\ 1- Pesquisador Doutor - Centro de Pesquisa em Florestas (DDPA/SEAPDR), Santa \\ Maria, Rio Grande do Sul - evandro.missio@gmail.com \\ 2- Pesquisador Doutor - Centro de Pesquisa em Florestas (DDPA/SEAPDR), Santa \\ Maria, Rio Grande do Sul. \\ 3- Pesquisadora Doutora - Centro de Pesquisa em Florestas (DDPA/SEAPDR), Santa \\ Maria, Rio Grande do Sul. \\ 4- Pesquisadora Doutora - Centro de Pesquisa em Florestas (DDPA/SEAPDR), Santa \\ Maria, Rio Grande do Sul. \\ 5- Pesquisadora Doutora - Centro de Pesquisa em Florestas (DDPA/SEAPDR), Santa \\ Maria, Rio Grande do Sul.
}

Recebido em: 04/10/2019 - Aprovado em: 30/11/2019 - Publicado em: 15/12/2019 DOI: 10.18677/EnciBio_2019B54

\begin{abstract}
RESUMO
Senna multijuga é uma espécie florestal nativa do território brasileiro com potencial de uso em diferentes áreas. Sua multiplicação ocorre via sementes, as quais apresentam a casca dura resultando em dormência tegumentar. $O$ objetivo deste trabalho foi avaliar a eficiência da escarificação mecânica com lixa em cilindro rotativo na superação da dormência tegumentar de sementes de $S$. multijuga. O delineamento experimental foi o inteiramente casualizado, formado por um fatorial de cinco tempos de escarificação mecânica $(0,5,10,15$ e 20 segundos) combinado com duas granulometrias de lixa (60 e 80 ), em quatro repetições. Posteriormente, foi efetuada uma comparação entre os melhores resultados do trabalho com a recomendação oficial para a superação de dormência. Foram avaliados o índice de velocidade de germinação, coeficiente de velocidade de germinação, tempo médio de germinação, porcentagens de germinação e sementes mortas. Houve diferenças significativas $(p<0,05)$ para a granulometria de lixa nos diferentes tempos de escarificação em cilindro rotativo para as variáveis analizadas. Os resultados apontam que a escarificação mecânica com lixa 80 em cilindro rotativo durante 10 segundos foi eficiente para a superação da dormência em $S$. multijuga.
\end{abstract}

PALAVRAS-CHAVE: Escarificação Mecânica, Germinação, Pau-Cigarra.

\section{OVERCOMING THE DORMANCY OF Senna multijuga (Rich.) H. S. Irwin \& Barneby SEEDS WITH THE USE OF SANDPAPER IN ROTARY CYLINDER}

\begin{abstract}
Senna multijuga is a native Brazilian forest species with potential for use in different areas. Its multiplication occurs via seeds, which have a hard shell resulting in integument dormancy. The objective of this study was to evaluate the efficiency of
\end{abstract}


mechanical scarification with sandpaper in rotary cylinder in overcoming the integument dormancy of $S$. multijuga seeds. The experimental design was completely randomized, consisting of a factorial with five mechanical scarification times $(0,5,10$, 15 and 20 seconds) and two sandpaper granulometry (60 and 80 ) in four replications. Subsequently, was proceeded a comparison between our best results and the official recommendation for overcoming dormancy. Germination speed index, germination speed coefficient, average germination time, germination percentages and dead seeds were evaluated. Significant differences $(p<0.05)$ were observed for sanding particle size at different rotary cylinder scarification times for the dependent variables analyzed. The results indicate that mechanical scarification with sandpaper 80 in rotary cylinder for 10 seconds can be recommended for the practice of overcoming dormancy in $S$. multijuga.

KEYWORDS: Mechanical Scarification, Germination, Pau-cigarra.

\section{INTRODUÇÃO}

Senna multijuga é conhecida popularmente como cassia-multijuga, paucigarra ou aleluia, é uma espécie florestal arbórea nativa com distribuição em quase todo o território brasileiro, especialmente no bioma Mata Atlântica (LORENZI, 2000). Pode ser propagada para utilização em programas de recuperação de áreas degradadas, construção civil, curtumes e paisagístico (CARVALHO, 2003).

A propagação de $S$. multijuga ocorre através de sementes, as quais apresentam dormência tegumentar e necessitam de superação para que ocorra uniformidade na germinação. Isto ocorre pelo fato do tegumento apresentar impermeabilidade imposta pela casca, o que dificulta a entrada de água na semente impedindo o processo de germinação (TAIZ et al., 2017; OLIVEIRA JUNIOR et al., 2018).

Diferentes recomendações são descritas na literatura para a superação da dormência de $S$. multijuga, como a embebição em água em temperatura ambiente (CARVALHO, 2004) ou aquecimento (ABDO; FABRI, 2015; RIBEIRO et al., 2016), ácido sulfúrico (SILVA et al., 2016) e ultrassom (VENANCIO; MARTINS, 2019). Contudo, o uso de ácido sulfúrico ou temperaturas elevadas podem ser potenciais causadores de danos ao embrião da semente, sendo que o ácido sulfúrico não é uma técnica segura para aplicação em rotinas de viveiro (MISSIO et al., 2018).

Neste sentido, deve-se buscar a recomendação de técnicas para a superação da dormência em sementes com enfoque em tecnologias que possam ser utilizadas tanto em laboratório como em viveiro. A padronização da metodologia é importante, pois permite que as sementes postas para germinar no viveiro possam expressar o mesmo potencial germinativo proporcionado em laboratório. Uma técnica que pode ser utilizada, no caso da dormência tegumentar, é a associação de lixa em cilindro rotativo.

Estudos recentes têm mostrado êxito com a utilização da lixa em cilindro rotativo, de forma isolada ou combinada, como metodologia para a superação da dormência física em sementes de Lithraea molleoides Vell. (Engl.) (MISSIO et al., 2018); Schinus terebentifolius Raddi (SALDANHA et al., 2017), Caesalpinia ferrea Mart. ex Tul. (MISSIO et al., 2016) e Schinus molle L. (LEAL, 2015). Em todos os estudos, o processo tecnológico gerado permitiu a recomendação da técnica tanto para laboratório como viveiro. O objetivo deste trabalho foi verificar a eficiência da escarificação mecânica com lixa em cilindro rotativo na superação da dormência tegumentar de sementes de $S$. multijuga. 


\section{MATERIAL E MÉTODOS}

O experimento foi conduzido no Laboratório de Análise de Sementes Florestais (LASF) do Centro de Pesquisa em Florestas, Santa Maria/RS. Foram utilizadas sementes da espécie Senna multijuga pertencentes ao lote $n^{\circ}$ 29/2017, com pureza de $99 \%$, umidade de $9,12 \%$ e peso de mil sementes (PMS) de 10,7 gramas. A coleta dos frutos foi efetuada em três árvores matrizes $\left(29^{\circ} 39^{\prime} 56,74^{\prime \prime} \mathrm{S}\right.$, $53^{\circ} 54^{\prime} 50,57^{\prime \prime}$ O) localizadas em ACS (Área de Coleta de Sementes). Após a secagem, os frutos foram beneficiados e as sementes armazenadas em câmara friaseca com temperatura $(6$ a $9 \stackrel{\circ}{\circ}$ ) e umidade relativa do ar variando de 30 a $60 \%$.

$O$ experimento foi realizado em delinamento inteiramente casualizado, sendo testados 10 tratamentos em esquema fatorial com cinco tempos de escarificação mecânica $(0,5,10,15$ e 20 segundos) combinados com duas granulometrias de lixa (60 e 80). Para cada tratamento foram utilizadas 200 sementes, subdivididas em quatro repetições de 50 sementes (BRASIL, 2013).

Para fins de validação do melhor resultado obtido, numa segunda etapa foi implantado um tratamento de superação de dormência com o uso da metodologia do pique manual recomendada por Brasil (2013) e o melhor resultado obtido no experimento anterior. Neste caso, foram comparados dois tratamentos [testemunha, pique (BRASIL, 2013) e melhor resultado obtido no experimento anterior] em delineamento inteiramente casualizado, com quatro repetições.

Para a realização da escarificação mecânica, foi utilizado um escarificador elétrico do tipo cilindro rotativo $\left(\mathrm{WEG}^{\oplus}\right)$ com diâmetro de $20 \mathrm{~cm}$ e quatro hastes giratórias, com rotação de $1.725 \mathrm{rpm}$. Para a escarificação das sementes foi utilizada uma lixa sem uso para cada um dos tratamentos, a fim de evitar a ocorrência de erros pelo desgaste de uso. Para fins de padronização, as sementes foram alocadas sob a lixa na parte inferior do cilindro, e posteriormente acionada o equipamento com o respectivo tempo de escarificação.

Após a aplicação dos tratamentos, as sementes foram imersas em hipoclorito de sódio $(2,5 \%)$ em solução na concentração de $5 \%(\mathrm{v} / \mathrm{v})$ durante cinco minutos, seguido da lavagem em água destilada e posterior semeadura em papel substrato do tipo mata-borrão em caixas tipo gerbox. O papel substrato de cada repetição foi umedecido com água destilada na proporção de duas vezes a sua massa (BRASIL, 2013) e após a inoculação das sementes, cada gerbox foi alocado num germinador do tipo Mangelsdorf com temperatura de $25 \pm 1^{\circ} \mathrm{C}$, onde permaneceu incubado durante as avaliações.

Foram avaliadas as seguintes variáveis: Índice de velocidade de germinação (IVG) - Determinado através de contagens diárias da germinação durante 14 dias, Os valores obtidos foram calculados pela seguinte fórmula (MAGUIRE, 1962): IVG = G1/N1 + G2/N2 + ... Gn/Nn; onde, IVG = índice de velocidade de germinação; $G 1, G 2, \ldots$ Gn = número de plântulas normais computadas na primeira contagem, na segunda contagem e na última contagem; N1, $\mathrm{N} 2, \ldots \mathrm{Nn}$ = número de dias da semeadura à primeira, segunda e última contagem; Coeficiente de velocidade de germinação (CVG) - Calculado pela e fórmula $\mathrm{CVG}=(\mathrm{G} 1+\mathrm{G} 2+\mathrm{G} 3+\ldots+\mathrm{Gi} / \mathrm{G} 1 \mathrm{~N} 1+\mathrm{G} 2 \mathrm{~N} 2+\mathrm{G} 3 \mathrm{~N} 3+\ldots+\mathrm{GiNi}) \quad \mathrm{x} \quad 100 ; \quad$ onde, $\quad \mathrm{CVG}=$ coeficiente de velocidade de germinação; $G=$ número de plântulas germinadas observadas em cada dia de contagem; $\mathrm{N}$ = número de dias da semeadura a cada contagem (KOTOWSKI, 1926); Tempo médio de germinação (TMG) - Calculado pela fórmula $T M G=(\mathrm{G} 1 \mathrm{~N} 1+\mathrm{G} 2 \mathrm{~N} 2+\mathrm{G} 3 \mathrm{~N} 3+\ldots+\mathrm{GiNi}) /(\mathrm{G} 1+\mathrm{G} 2+\mathrm{G} 3+\ldots+\mathrm{Gi})$, onde: $\mathrm{TMG}$ = tempo médio de germinação; $G$ = número de plântulas germinadas observadas em 
cada dia de contagem; $\mathrm{N}=$ número de dias da semeadura a cada contagem (SANTANA; RANAL, 2004); Germinação - Adaptado de Brasil (2013), foi realizada com quatro subamostras de 50 sementes, sendo as contagens realizadas aos quatro e sete dias após a incubação, sendo as sementes germinadas posteriormente descartadas, com o resultado expresso em porcentagem. Para fins de padronização, neste trabalho foi convencionado como germinação a semente que emitiu a radícula com no mínimo $2 \mathrm{~mm}$ de comprimento; Sementes mortas - Realizada concomitantemente com a germinação acumulada, sendo que as sementes que não germinaram, foram classificadas como mortas. Em cada avaliação, assim como ocorreu com as sementes germinadas, aquelas consideradas mortas foram descartadas. O resultado foi expresso em porcentagem.

Os dados foram submetidos à análise da variância e, posteriormente efetuando-se regressão ou teste de médias (Tukey) para variáveis que apresentaram significância a $5 \%$ de probabilidade de erro, com auxílio do software estatístico Sisvar 5.6 (FERREIRA, 2011).

\section{RESULTADOS E DISCUSSÃO}

\section{Tempos de escarificação e granulometria de lixa}

A estatística mostrou que houve interação entre tempo de escarificação e granulometria de lixa para todas as variáveis dependentes analisadas. $O$ índice de velocidade de germinação (IVG) apresentou comportamento quadrático, em que o tempo de 10 segundos de escarificação das sementes de Senna multijuga em lixa 80 resultou no maior número de sementes com emissão de radícula/dia (Figura 1a), com IVG de 15,8 e ponto de máxima eficiência técnica (PMET) em 13,3 segundos. Quando comparado à lixa 60 no tempo de 10 segundos, o IVG das sementes em lixa 80 foi 5,6 vezes superior. Também foi observado que o tempo de 10 segundos de escarificação em lixa 80 proporcionou IVG 9,7 vezes superior ao tratamento sem escarificação. A escarificação mecânica com o uso de lixa também resultou em elevado IVG em trabalhos com sementes de Schizolobium amazonicum (CARVALHO et al., 2019) e Hymenaea stigonocarpa Mart. ex Hayne (RIBEIRO et al., 2017).

Com relação ao tempo médio de germinação (TMG), as sementes submetidas à escarificação em 15 segundos (PMET) com lixa 80 desencadearam o processo de germinação mais rapidamente (1,7 dias), porém, com os valores semelhantes ao tempo de 10 segundos de escarificação (1,7 dias) (Figura 1b). Cabe destacar que ambos os tempos resultaram numa redução de aproximadamente $26 \%$ no tempo médio de germinação em relação ao tratamento sem escarificação das sementes.

O coeficiente de velocidade de germinação (CVE) expressou comportamento relacionado ao TMG, em que a diminuição no TMG aumenta a eficiência do CVE. Sementes de S. multijuga submetidas à lixa 80 nos tempos de 10 e 15 segundos apresentaram maior precocidade de germinação, com resultados idênticos (Figura 1c) e PMET no tempo de 11,1 segundos. O CVE está relacionado com a precocidade de germinação, ou seja, sementes que conseguirem absorver água mais rapidamente, também terão maior precocidade na germinação.

Confrontando os resultados obtidos no IVG, TMG, e CVG, pode-se constatar que o tempo de 10 segundos de escarificação em cilindro rotativo com lixa 80, resultou em maior número de plântulas dias (IVG), num menor tempo de germinação (TMG), influenciado por uma maior precocidade (CVG) proveniente de um 
rompimento mais eficiente da casca, causado pela abrasividade da lixa nas sementes de S. multijuga. Em sementes de L. molleoides Missio et al. (2018) obtiveram resultados satisfatórios para o IVG, TMG, CVG e germinação quando submeteram as sementes à escarificação mecânica com lixa 80 em cilindro rotativo associado à água a $70 \stackrel{\circ}{\circ}$.

(a)

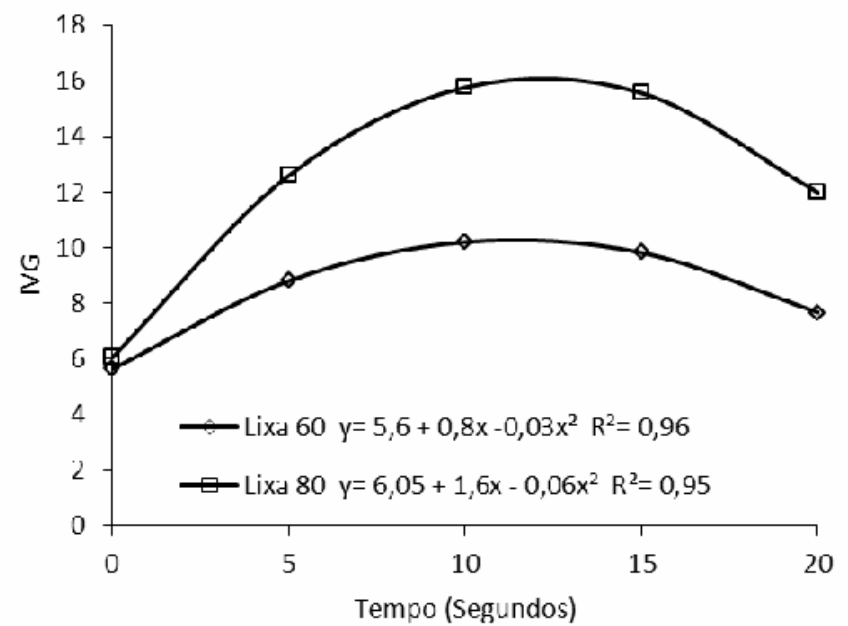

(b)

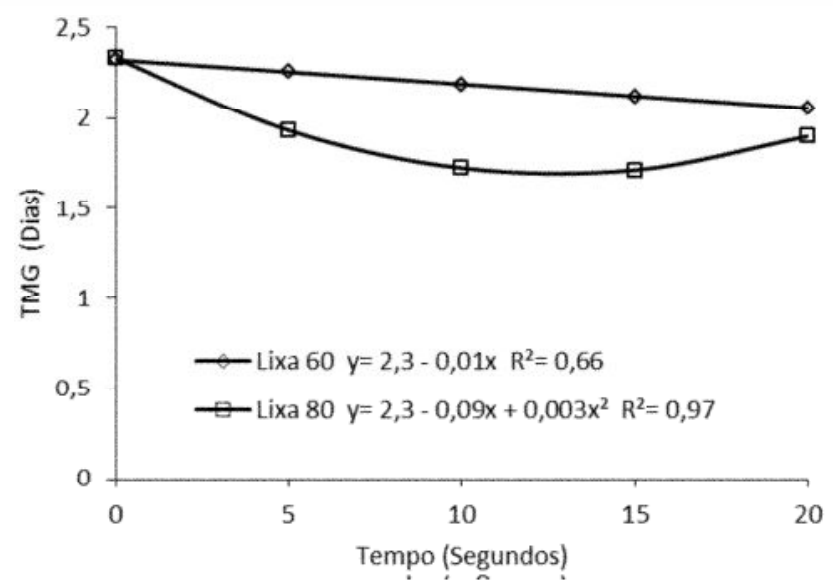

(c)

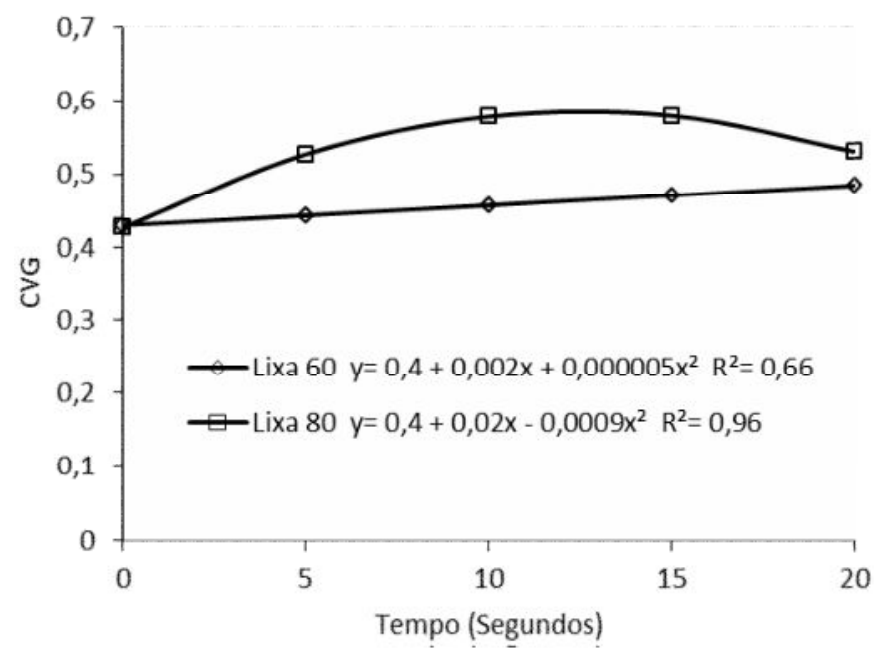

FIGURA 1 - Índice de velocidade de germinação (IVG) (a), tempo médio de germinação (TMG) (b) e coeficiente de velocidade de germinação (CVG) (c) de sementes de $S$. multijuga submetidas a duas granulometrias de lixa e cinco tempos de escarificação em cilindro rotativo. 
A germinação das sementes de $S$. multijuga apresentou comportamento quadrático positivo para as duas granulometrias de lixa em diferentes tempos de escarificação em cilindro rotativo (Figura 2a). Os tempos de 10 e 15 segundos de escarificação em lixa 80 resultaram nos maiores percentuais de germinação (98\%), apresentando $44 \%$ a mais na germinação em comparação à testemunha sem escarificação, e com PMET em 18,2 segundos.

Também foi observado que para todos os tempos testados em lixa 80 resultaram em maior germinação que em lixa 60 , sendo que a distância entre pontos percentuais tornou-se mais acentuada à medida que os tempos foram aumentados. A explicação provável é o fato de que a granulometria maior da lixa 60 possa ter ocasionado danos mais acentuados às sementes de S. multijuga. Em Cassia leptophylla a comparação entre diferentes metodologias de superação da dormência mostrou que o pique manual com tesoura resultou em germinação superior a $90 \%$, sendo o melhor resultado (ROCHA et al., 2018).

Quanto ao percentual de sementes mortas, as equações apresentadas na figura $2 \mathrm{~b}$ mostram o oposto apresentado na figura $2 \mathrm{a}$. As sementes do tratamento testemunha apresentaram elevadas porcentagens de sementes mortas. Tal fato pode ser atribuído ao tempo em que as sementes permaneceram em ambiente com temperatura e umidade controladas, porém, com impedimento de absorver água devido à rigidez do tegumento, o que facilitou o processo de deterioração e consequente morte. Também se observa que no tempo de 20 segundos ocorreram elevados percentuais de sementes mortas sendo a causa provável o tempo de exposição à lixa.

(a)

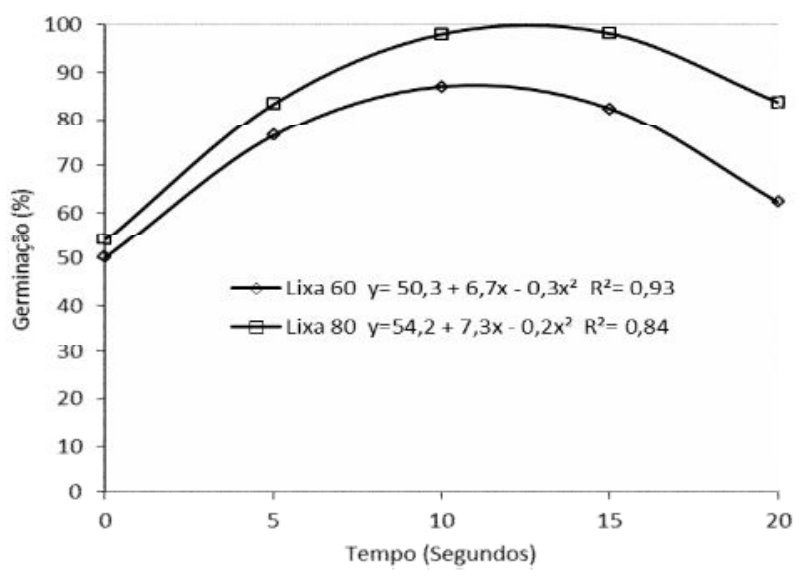

(b)

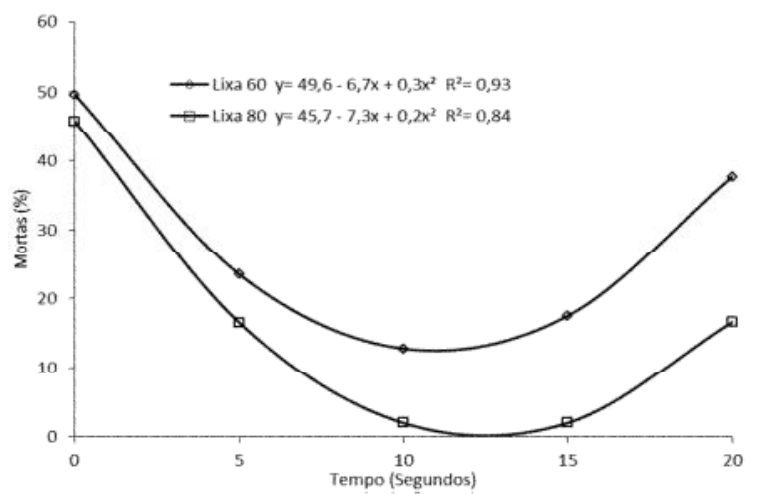

FIGURA 2 - Porcentagem de germinação (a) e de sementes mortas (b) de sementes de $S$. multijuga submetidas a duas granulometrias de lixa e cinco tempos de escarificação em cilindro rotativo. 


\section{Lixa em cilindro rotativo $x$ Pique}

Houveram diferenças significativas entre o melhor método obtido neste estudo em comparação àquele recomendado por Brasil (2013) (Tabela 1). A escarificação das sementes de $S$. multijuga com lixa 80 durante 10 segundos em cilindro rotativo proporcionou maior IVG, CVG e G menor, além de menor TMG, em relação às sementes que foram submetidas ao pique. Este resultado também refletiu no baixo percentual de sementes mortas no tratamento envolvendo o uso do cilindro rotativo.

TABELA 1 - Índice de velocidade de germinação (IVG), tempo médio de germinação (TMG), coeficiente de velocidade de germinação (CVG), porcentagem de germinação $(G)$ e porcentagem de sementes mortas $(M O)$ de sementes de $S$. multijuga submetidas a dois métodos de escarificação.

\begin{tabular}{lccccc}
\hline MÉTODO & IVG & TMG & CVG & G (\%) & MO (\%) \\
\hline Lixa $^{(1)}$ & $15,10 \mathrm{a}$ & $1,78 \mathrm{~b}$ & $0,56 \mathrm{a}$ & $95 \mathrm{a}$ & $5 \mathrm{~b}$ \\
Pique $^{(2)}$ & $9,00 \mathrm{~b}$ & $2,11 \mathrm{a}$ & $0,47 \mathrm{~b}$ & $74 \mathrm{~b}$ & $26 \mathrm{a}$ \\
& & & & & \\
\hline $\begin{array}{l}\text { Média } \\
\text { geral }\end{array}$ & 12,05 & 1,95 & 0,51 & 84,5 & 15,5 \\
\hline CV $(\%)$ & 8,64 & 5,35 & 5,20 & 7,17 & 15,5
\end{tabular}

(1) Lixa no 80 e tempo de 10 segundos em cilindro rotativo. (2) Pique manual com o uso de tesoura (Brasil, 2013). Médias nas colunas seguidas por letras iguais não diferem pelo teste de Tukey a $5 \%$ de probabilidade de erro.

As informações mostradas na tabela 1 evidenciam a eficiência da metodologia associando granulometria de lixa e tempo em motor elétrico equipado com cilindro rotativo. Esta prática simples, rápida e de baixo custo, pode ser recomendada não somente para rotinas laboratoriais, mas também em viveiros, onde se trabalha com grandes quantidades de sementes, e se deseja uma metodologia executável e que possa propiciar a melhor forma para a expressão do potencial fisiológico da semente após a semeadura. No caso dos viveiros, o uso do cilindro rotativo permite ainda que um maior número de sementes possam ser submetidas simultaneamente à escarificação em cilindro rotativo, enquanto que o pique, por exemplo, é realizado de forma individual em cada semente. Segundo Ribeiro et al. (2017) a escarificação com lixa é uma metodologia sustentável para a superação da dormência em determinadas espécies, pois além de não deixar resíduos ao meio ambiente e ao homem, pode ser menos danoso ao embrião da semente quando comparado a outros métodos.

Outra vantagem é a possibilidade de a lixa em cilindro rotativo proporcionar uma escarificação em várias posições da superfície tegumentar, diferente do pique, onde ocorre corte somente em uma das extremidades. Com isso, a água penetra em diferentes locais da semente, facilitando o início do processo de germinação, e a nova plântula pode romper com maior facilidade o invólucro tegumentar, o qual está fragilizado pela ação da lixa. Os resultados obtidos nas figuras 1 e 2 e tabela 1 , validam a metodologia para a superação da dormência tegumentar de $S$. multijuga com lixa 80 no tempo de 10 segundos de exposição das sementes em cilindro rotativo.

\section{CONCLUSÃO}

A escarificação mecânica com lixa 80 em cilindro rotativo durante 10 segundos é recomendada para a superação da dormência em S. Multijuga. 


\section{REFERÊNCIAS}

ABDO, M.T.V.N.; FABRI, E.G. Transferência de tecnologia: guia prático para quebra de dormência de sementes de espécies florestais nativas. Pesquisa \& Tecnologia, v. 12, n. 2, p. 1-7, 2015. Disponível em: http://www.aptaregional.sp.gov.br/acesse-osartigos-pesquisa-e-tecnologia/edicao-2015/julho-dezembro-3/1670-tecnologia-guiapratico-para-quebra-de-dormencia-de-sementes-de-especies-florestaisnativas/file.html. Acesso em 11 de setembro de 2019.

BRASIL. Ministério da Agricultura e Reforma Agrária. Instruções para análise de sementes de espécies florestais. Brasília: SNDA/CGAL, 2013. 97 p.

CARVALHO, P. E. R. Espécies Arbóreas Brasileiras. Brasília: EMBRAPA Informação Tecnológica. Colombo, PR: EMBRAPA Florestas, v. 1, 2003. 1039 p.

CARVALHO, P.E.R. (2004). Pau-cigarra - Senna multijuga. Colombo, Embrapa Florestas. 11p.

CARVALHO, M.B.F.; ARAUJO, M.E.R.; MENDONÇA, A.P.; CHÁVEZ, M.S.; GUTIERREZ, K.L. et al. Métodos de superação de dormência da Schizolobium amazonicum Huber ex Ducke. Brazilian Journal of Animal and Environment Research, v. 2, n. 1, p. 490-500, 2019. Disponível em: http://www.brjd.com.br/index.php/BJAER/article/view/1436. Acesso em 10 de setembro de 2019.

FERREIRA, D.F. Sisvar: a computer statistical analysis system. Ciência e Agrotecnologia, v. 35, n. 6, p. 1.039-1.042, 2011. Disponível em: http://dx.doi.org/10.1590/S1413-70542011000600001. Acesso em 12 de agosto de 2019.

KOTOWSKI, F. Temperature relations to germination of vegetable seeds. Procedures American Horticultural Science, v. 23, p. 176-184, 1926.

LEAL, C.M. Superação de dormência e produção de mudas de anacauíta Schinus molle L. 2015. 90 f. Dissertação. (Mestrado em Ciência e Tecnologia de Sementes) - Universidade Federal de Pelotas, Pelotas. 2015. Disponível em: http://guaiaca.ufpel.edu.br/handle/prefix/4060. Acesso em 10 de setembro de 2019.

LORENZI, H. Árvores Brasileiras: Manual de Identificação e Cultivo de Plantas Arbóreas Nativas do Brasil. Nova Odessa: São Paulo, 2000. 352 p.

MAGUIRE, J. D. Speed of germination-aid in selection and evaluation for seedling emergence and vigor. Crop Science, v. 2, n. 1, p. 176-177, 1962. Disponível em: <https://dl.sciencesocieties.org/publications/cs/abstracts/2/2/CS0020020176>. doi: 10.2135/cropsci1962.0011183X000200020033x. Acesso em 10 de setembro de 2019.

MISSIO, E.L; SALDANHA, C.W.; MALDANER, J.; MORAIS, R.M. De; STEFFEN, J.P.K. Escarificação mecânica em cilindro rotativo é viável para a superação da dormência de sementes de pau-ferro. Enciclopédia Biosfera, v. 13, n .24, p. 476- 
485 ,

2016

Disponível

em:

http://www.conhecer.org.br/enciclop/2016b/agrarias/escarificacao.pdf.

Doi:

10.18677/EnciBio_2016B_043. Acesso em 10 de setembro de 2019.

MISSIO, E.L; SALDANHA, C.W.; MALDANER, J.; STEFFEN, J.P.K.; MORAIS, R.M. De. A combinação entre a escarificação mecânica e térmica é eficiente para a superação da dormência das sementes de Lithraea molleoides. Enciclopédia Biosfera, v. 15. n. 28, p. 11-21, 2018. Disponível em: https://www.conhecer.org.br/enciclop/2018B/AGRAR/a\%20combinacao.pdf. Doi: 10.18677/EnciBio_2018B2. Acesso em 09 de setembro de 2019.

OLIVEIRA JUNIOR, A.B.; REIS, D.R.; SANTOS, I.N.R; NETO, J.E.E.; FERREIRA, M.A. et al. Identificação de dormência tegumentar em sementes florestais através do estudo da curva de embebição. Revista Intercâmbio, v. 11, n. 1, p. 161-173, 2018. Disponível

em: http://www.intercambio.unimontes.br/index.php/intercambio/article/view/252. Acesso em 09 de setembro de 2019.

RIBEIRO, D.E.; ALVARENGA, A.A.; MARTINS, J.R.; RODRIGUES, A;C.; MAIA, V.O. Germinação e reindução da tolerância à dessecação em sementes de Senna multijuga (Rich.) Irwin et Barn. Ciência Florestal, v. 26, n. 4, p. 1133-1140, 2016. Disponível em: http://www.scielo.br/scielo.php?pid=S198050982016000401133\&script=sci_abstract\&tlng=pt. Acesso em 09 de setembro de 2019.

RIBEIRO, E.A.; FREITAS, G.A.; FREITAS, M.A.B.P.; SANTOS, A.C.M.; BESSA, N.G.F. et al. Métodos sustentáveis para a superação da dormência em sementes de jatobá do cerrado. Technology \& Science Agropecuary, v. 11, n. 6, p. 119-124, 2017. Disponível em: http://revistatca.pb.gov.br/edicoes/volume-11-2017/v-11-n-6dezembro-2017/16-artigo-ce-1017-01-metodos-para-superacao-de-dormencia-emsementes-de-jatoba.pdf. Acesso em: 10 de setembro de 2019.

ROCHA, N.M.; SILVA, J.E.S. Da; MELO JUNIOR, J.L.A.; MELO, L.D.F.A.; NETO, J.C.A. et al. Superação da dormência em sementes de Cassia leptophylla Vogel. Revista Craibeiras de Agroecologia, v. 3, n. 1, p. e6608, 2018. Disponível em: http://www.seer.ufal.br/index.php/era/article/view/6608. Acesso em 10 de setembro de 2019.

SALDANHA, C.W.; MORO, T.S.; MISSIO, E.L; MALDANER, J.; STEFFEN, J.P.K. Escarificação mecânica e química na germinação de sementes de Schinus terebinthifolius Raddi. Enciclopédia Biosfera, v. 14, n .25, p. 519-529, 2017. Disponível em: http://www.conhecer.org.br/enciclop/2017a/agrar/escarificacao\%20mecanica.pdf. Doi: 10.18677/EnciBio_2017A47. Acesso em 11 de setembro de 2019.

SANTANA, D.G.; RANAL, M.A. Análise da germinação: um enfoque estatístico. Brasília: UnB, 2004. 247 p. 
SILVA, E.; GUILHERME, M.F.S.; SANTOS, P.S. Morphometric characterization and overcoming of dormancy by chemical agent in seeds of Senna multijuga (Rich.). Revista da Universidade Vale do Rio Verde, v. 14, n. 1, p. 1098-1106, 2016. Disponível em: http://periodicos.unincor.br/index.php/revistaunincor/article/view/2916. DOI: http://dx.doi.org/10.5892/ruvrd.v14i1.2916. Acesso em 11 de setembro de 2019.

TAIZ, L.; ZEIGER, E.; MOLLER, I.M.; MURPHY, A. Fisiologia e desenvolvimento vegetal. Porto Alegre: Artmed, 2017. 888 p.

VENÂNCIO, R.S.S.; MARTINS, A.C.G. Overcoming dormancy of Senna multijuga seeds with an ultrasonic probe the comparison with ultrasound and sulfuric acid baths. Ciência Rural, v. 49, n. 9, e20180904, 2019. Disponível em: http://dx.doi.org/10.1590/0103-8478cr20180904. Acesso em 24 de setembro de 2019. 